\section{Psychopathology of Eating Disorders According to Neurobiology of Attachment: An Instrument to Overcome Resistances to Treatment?}

\author{
Federico Amianto \\ Coordinator of Neuroimaging Research on \\ Eating Disorders \\ Corresponding author: Amianto $\mathrm{F}$
}

”federico.amianto@unito.it

Received: June 19, 2015; Accepted: June 22, 2015; Published: June 25, 2016

Eating disorders are still challenging mental disorders and encourage psychiatrists to wide-range reflections on their psychopathology which are addressed to copy with the persisting difficulties in offering an effective treatment. The current development of the treatments for EDs is still unsatisfactory, in particular for Anorexia Nervosa (Zipfel et al., 2013) [1]. More or less one half of subjects affected with bulimia nervosa and one fourth of those affected with anorexia nervosa reach a complete and lifetime stable recovery from their disease. The resistances to treatment (e.g. difficulty in engaging in the treatment, in being compliant to therapies, and in concluding the therapeutic programs in agreement with the therapists) which are common to all mental disorders are expressed at their highest degree in ED subjects (Fassino and Abbate Daga, 2013 [2]; Abbate Daga et al., 2013 [3]). The psychopathological models of the eating disorders, which are the basis of worldwide validated treatments (Fairburn et al., 2015 [4]; Zipfel et al., 2013) are still far from effectively explaining the dynamics underlying the resistances to treatment and offer effective solutions. Thus the resistances to treatment are worldwide challenging the current clinical practice concerning EDs since they impair treatment search and compliance, foster dropout, obstacle recovery, and in general delay healing.

The early psychopathological theories concerning the pathogenesis of EDs (Bruch, 1982) [5] were recently proposed by psychodynamic psychotherapists as an interpretative model which could significantly improve current treatment of eating disorders (Skarderud, 2009) [6]. In particular Hilde Bruch conceives severe eating disorders as a consequence of a deficit in the structure of the Self and she relates the deficit of the development of the Self to problems in the relationship with the caregiver. In particular, according to Winnicott (1973) [7], Bruch sustains that the inadequate recognition of infants' needs operated by the caregiver exerts in the impairment of the development of Selfconsciousness.

The central role of the caregivers in the development of the Self is consistent with the hypothesis of Bolwby (1907-1990) and his disciples that attachment is fundamental for the construction of the Self. Recent literature revision concerning the problems of attachment in EDs and their influence on the development
Research Coordinator Department of Neurosciences, University of Torino, Italy.

Tel: +393387813863

Citation: Amianto F. Psychopathology of Eating Disorders According to Neurobiology of Attachment: An Instrument to Overcome Resistances to Treatment?. Acta Psychopathol. 2015, 1:1.

of the functions of the Self (e.g. reflective functioning, emotion regulation, conceits about the self and others, and relationship management) (Tasca \& Balfour, 2014a) [8] encouraged Tasca and Balfour (2014b) [9] to propose a psychodynamic model of eating disorders based on the role of distorted attachment dynamics as the core of future therapeutic development in ED's.

Recently, a substantial support to the relevance of attachment in the construction of the Self also derives from neurobiological acquisitions. The recent discovery of the existence of a mirror neurons system, and the conceptualization of the mechanisms of the Intentional Attunement and Embodied Simulation by Gallese and coworkers $(2007 a$, b) $[10,11]$ claim that the attunement between mother and child is "the shared intersubjective space in which we live since birth" which "enables and bootstraps the constitution of the sense of identity we normally entertain with others" (Gallese, 2009) [12]. Also the evidences on brain synchronization with EEG frequencies support that the communication between individuals involved in a deep attachment relationship produces evident changes in the electrical functioning of the brain in both subjects involved, and that this synchronization is basic for communication between subjects (Northoff, 2013) [13].

Thus, not only the relational attitudes described as attachment patterns are definite by the first interactions with the caregiver and will constitute the basis for the future relational interaction (included the therapeutic relationship), but the psychological functioning pertaining the Self and the related structures of the brain are modified in the subjects affected with eating disorders by their early interactions with their caregivers, and these 
alterations are strictly related to their eating psychopathology (Amianto et al., 2013a,b [14,15]; Cicereale et al., 2014 [16]; D’Agata et al., 2015 [17]; Lavagnino et al., 2014, 2015) [18, 19].

A consequence of these evidences is that subjects with eating disorders are profoundly suffering because of an insufficiently developed sense of the Self which is consequent to an inadequate attachment with their caregivers (Bruch, 1982). They need to build a vicarious relationship with the new caregivers who are the therapists (Gulliksen et al., 2012) [20] to complete their Self-development, but their brain structures which are modeled by their early attachment relations obstacle them in building new and more effective relationships. These subjects are often scared by their perception of the others, and the interiorized image of devaluating and unfaithful caregivers produces transferal reactions which are highly ambivalent and often obstacle the caring relationship (Vitousek and Watson, 1998) [21]. Only the attitudes, we could say virtues (Brenner and Kahn, 2013) [22], of the current caregiver, which is the therapist, who involves the patients in an affective, reliable, trustful, validating, respectful relationship (Fassino, 2014) [23] represent the beginning of the reconstruction of new parts of the Self by means of the same neurobiological mechanisms of intentional attunement and embodied simulation that were insufficient in early infancy. These new neurobiological interactions will progressively modify the structure and the tropisms of brain circuits related to attachment, and possibly stabilize a new healthy existence. 


\section{References}

1 Zipfel S, Wild B, Groß G, Friederich HC, Teufel M, et al. (2014) Focal psychodynamic therapy, cognitive behaviour therapy, and optimised treatment as usual in outpatients with anorexia nervosa (ANTOP study): randomised controlled trial. Lancet 383:127-137.

2 Fassino S, Abbate-Daga G (2013) Resistance to treatment in eating disorders: a critical challenge. BMC Psychiatry 13: 282.

3 Abbate-Daga G, Amianto F, Delsedime N, De-Bacco C, Fassino S (2013) Resistance to treatment and change in anorexia nervosa [corrected]: a clinical overview. BMC Psychiatry 13: 294.

4 Fairburn CG, Bailey-Straebler S, Basden S, Doll HA, Jones R, et al. (2015) A transdiagnostic comparison of enhanced cognitive behaviour therapy (CBT-E) and interpersonal psychotherapy in the treatment of eating disorders. Behav Res Ther 70: 64-71.

5 Bruch H (1982) Anorexia Nervosa: therapy and theory. Am J Psychiatry 139: 1531-1538.

6 Skårderud F (2009) Bruch revisited and revised. Eur Eat Disord Rev 17: 83-88.

7 Winnicott DW (1973) The Child, the Family, and the Outside World (Middlesex 1973) p. 75-6.

8 Tasca GA, Balfour L (2014) Attachment and eating disorders: a review of current research. Int J Eat Disord 47: 710-717.

9 Tasca GA, Balfour L (2014) Eating disorders and attachment: a contemporary psychodynamic perspective. Psychodyn Psychiatry 42: 257-276.

10 Gallese V (2007) Before and below 'theory of mind': embodied simulation and the neural correlates of social cognition. Philos Trans R Soc Lond B Biol Sci 362: 659-669.

11 Gallese V, Eagle MN, Migone P (2007) Intentional attunement: mirror neurons and the neural underpinnings of interpersonal relations. $J$ Am Psychoanal Assoc 55: 131-176.

12 Gallese V, Sinigaglia C (2010) The bodily self as power for action. Neuropsychologia 48: 746-755.
13 Northoff G (2013) Unlocking the brain: Volume 2: Consciousness. Oxford University Press: New York.

14 Amianto F, Caroppo P, D'Agata F, Spalatro A, Lavagnino L, et al. (2013) Brain volumetric abnormalities in patients with anorexia and bulimia nervosa: a voxel-based morphometry study. Psychiatry Res 213: 210-216.

15 Amianto F, D'Agata F, Lavagnino L, Caroppo P, Abbate-Daga G et al (2013) Intrinsic connectivity networks within cerebellum and beyond in eating disorders. Cerebellum 12:623-631.

16 Cicerale A, Settanta C, D'Agata F, Caglio M, Caroppo $P$ et al (2013) Neuroanatomical correlates of state of mind with respect to attachment in patients with anorexia nervosa. Clinical Neuropsychiatry 10, 5, 217-225.

17 D'Agata F, Caroppo P, Amianto F, Spalatro A, Caglio MM et al. (2015) Brain correlates of alexithymia in eating disorders: a voxel-based morphometry study. Psychiatry Clin Neurosci.

18 Lavagnino L, Amianto F, D'Agata F, Huang Z, Mortara P et al. (2014) Reduced resting-state functional connectivity of the somatosensory cortex predicts psychopathological symptoms in women with bulimia nervosa. Front Behav Neurosci 8: 270.

19 Lavagnino L, Amianto F, Mwangi B, D'Agata F, Spalatro A et al. (2015) Identifying neuroanatomical signatures of anorexia nervosa: a multivariate machine learning approach. Psychol Med 20: 1-8.

20 Gulliksen KS, Espeset EM, Nordbø RH, Skårderud F, Geller J, et al. (2012) Preferred therapist characteristics in treatment of anorexia nervosa: the patient's perspective. Int J Eat Disord 45: 932-941.

21 Vitousek K, Watson S, Wilson GT (1998) Enhancing motivation for change in treatment-resistant eating disorders. Clin Psychol Rev 18: $391-420$

22 Brenner A, Khan F (2013) The training of psychodynamic psychiatrists: the concept of "psychodynamic virtue". Psychodyn Psychiatry 41: 57-74.

23 Fassino S (2015) The resistance to treatment in anorexia nervosa: Adlerian psychodynamic psychotherapy has a specific indication? Journal of Individual Psychology 76: 31-69. 